At Turots: Jurnal Pendidikan Islam
Vol. 3, No.1, Juni 2021, pp. 66-78
Print ISSN : 2656-7555 || Online ISSN : 2747-089X
http://journal.stitmadani.ac.id/index.php/JPI/index

\title{
Metode pembelajaran berbasis qantum learning di pondok pesantren yatim dan dhuafa AR. Fakhruddin Prambanan
}

\author{
Adi Haironi a,1, ${ }^{*}$, Umar Saiful Haqb,2, Rendiansyah c,3 \\ *a UIN Sunan Kalijaga Yogyakarta, Indonesia; \\ b Sekolah Tinggi Ilmu Tarbiyah Madani Yogyakarta, Indonesia; \\ c Sekolah Tinggi Ilmu Tarbiyah Madani Yogyakarta, Indonesia. \\ ${ }^{1}$ Adihaironi85@gmail.com; ${ }^{2}$ Mislaaufayogya@gmail.com; ${ }^{3}$ Suyono20@stitmadani.ac.id; \\ *Correspondent Author
}

KATAKUNCI

Metode Pembelajaran;

Pondok Pesantren;

Quantum Learning; Yatim

Dhuafa

KEYWORDS

Learning methods; Islamic Boarding School; Quantum Learning; Orphans .

\section{ABSTRAK}

Artikel ini merupakan penelitan lapangan yang menggunakan pendekatan Fenomenologi. Analisis data yang digunakan adalah analisis kualitatif. Fenomena metode pembelajaran yang ada di sekolah, khususnya pondok pesantren dirasakan belum komprehensif bagi siswa untuk belajar. Padahal seharusnya lingkungan pondok pesantren dapat menjadi wadah untuk mengaplikasikan keilmuaan siswa dalam kehidupan sehari-hari. Adanya Pendekatan quantum learning berupaya untuk memanfaatkan secara optimal potensi atau kemampuan dasar yang dimiliki manusia dengan melakukan berbagai cara atau teknik yang melibatkan keseluruhan kepribadian baik intelek, fisik, maupun emosi. Pondok pesantren memiliki program unggulan keislaman yang merupakan pengembangan dari metode quantum learning yang meggabungkan aspek sugestology, teknik percepatan belajar dan neurolinguistik (NLP), para siswa diarahkan mengikuti kegiatan yang telah ditetapkan pondok pesantren, diantaranya yaitu Kegiatan Ikatan Pemuda Muhammadiyah (IPM), Tapak Suci (TS), Hizbul Wathan (HW), khitobah, membaca hadits, dan Bimbingan Baca Qur'an (BBQ) yang dilakukan secara kontinu. Dengan penggunaan quantum learning membuat siswa dapat menemukan sendiri jawaban atas permasalahan dan beraktivitas sesuai dengan tujuan yang ingin dicapai.

\section{Metode pembelajaran berbasis qantum learning dipondok pesantren yatim dan dhuafa AR. Fakhruddin Prambanan}

This article is a field research that uses the phenomenology approach. Data analysis used in this article is qualitative analysis. Phenomenonthe existing learning methods in schools, especially Islamic boarding schools, are felt to be not comprehensive for students to learn. In fact, the boarding school environment should be a place to apply students' knowledge in their daily lives. Existence Approach quantum learning trying to optimally utilize the potential or basic abilities possessed by humans by carrying out various methods or techniques that involve the whole personality both intellectually, physically, and emotionally. Islamic boarding school has a superior Islamic program which is the development of the quantum learning method combines aspects of suggestology, accelerated learning techniques and neurolinguistics (NLP), students are directed to participate in activities that have been established by the boarding school, 
including the Muhammadiyah Youth Association (IPM), Tapak Suci (TS), Hizbul Wathan (HW), khitobah, reading hadiths, and Quran Reading Guidance (BBQ) which is carried out continuously. With the use of quantum learning, students can find their own answers to problems and do activities in accordance with the objectives to be achieved. .

This is an open-access article under the CC-BY-SA license.

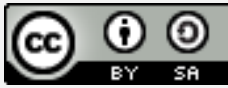

\section{Pendahuluan}

Sepanjang sejarah kehidupan manusia, pendidikan merupakan pokok dan hal yang harus dipenuhi sepanjang hayat. Tanpa adanya pendidikan sama sekali maka mustahil manusia dapat mencapai peradaban yang maju. Dalam bentuk yang sederhana dapat dipahami bahwa pendidikan sudah dijalankan sejak dimulainya kehidupan manusia di muka bumi, ini berarti pendidikan berkembang serta berproses bersama-sama dengan proses perkembangan hidup dan kehidupan manusia sendiri (Islam, 1995). Manusia sebagai tema sentral dalam sebuah proses pendidikan dalam perkembangannya banyak dipengaruhi oleh pembawaan dan lingkungan (Tafsir, 1992).

Pendidikan pada hakikatnya bukan hanya sekedar mentransfer ilmu saja. Tetapi lebih dari itu, pendidikan dalam Islam memberikan kesempatan dan mempersiapkan mental siswa dalam mengarungi kehidupan dan dapat memecahkan segala bentuk persoalan yang akan dihadapi. Problematika pendidikan Islam tidak bisa terlepas dari ruang lingkup pendidikan sendiri. Pokok ruang lingkup pendidikan ini terbagi menjadi tiga yaitu sekolah, rumah dan lingkungan (Pahnila et al., 2018).

Dari berbagai macam problem yang ada, penulis mengambil salah-satu contoh problematika yaitu pada metode pendidikan. metode yang ada di sekolah, khususnya pondok pesantren dirasakan belum komprehensif bagi siswa untuk belajar. Padahal seharusnya lingkungan pondok pesantren dapat menjadi wadah untuk mengaplikasikan keilmuaan siswa dalam kehidupan sehari-hari, yang notabene mereka hidup 24 jam di dalam pesantren.

Sementara ini sebelum diterapkannya model pendidikan quantum learning, kondisi yang ditemukan oleh peneliti adalah siswa belum memiliki kepribadian muslim sesuai yang diharapkan, dalam pergaulan sehari-hari kurang menunjukan sikap akhlakul karimah yang baik dengan para pembina maupun dengan sesamanya, dan proses pendidikan kurang terjadwal dengan baik. Maka penulis tertarik untuk meneliti bagaimana kondisi siswa setelah diterapkannya model quantum learning di pondok pesantren AR. Fakhruddin Prambanan.

Berkaca dari hal tersebut, seharusnya pondok pesantren mempunyai metode pembelajaran yang benar-benar serius dalam mengembangkan potensi atau kemampuan 
dasar yang dimiliki oleh setiap siswa. Contoh yang bisa dilakukan adalah menerapkan pembiasaan sholat berjamaah di pondok pesantren, mengadakan tausiyah atau kultum keislaman seusai shalat berjamaah, mengadakan kegiatan-kegiatan yang menarik bagi siswa, dan juga yang lainnya.

Pendekatan quantum learning berupaya untuk memanfaatkan secara optimal potensi atau kemampuan dasar yang dimiliki manusia dengan melakukan berbagai cara atau teknik yang melibatkan keseluruhan kepribadian baik intelek, fisik, maupun emosi (Murcia \& Sanchez, 2013). Quantum learning berasal dari falsafah dasar yang mendasari semua kurikulum yang ada. Dalam mendukung falsafah dasar tersebut metode quantum learning perlu disuport dengan lingkungan yang mendukung, sehingga seluruh siswa merasa penting, aman dan nyaman.

\section{Metode Penelitian}

Penelitian ini menggunakan jenis penelitian kualitatif dengan menggunakan pendekatan fenomenologi, penelitian dilakukan di Pondok pesantren AR. Fakhruddin Prambanan dengan metode pengumpulan data yang digunakan adalah dalam wawancara (interview), observasi dan Dokumentasi. Adapaun dalam menganalisis data menggunakan deskriptif analitis (DePorter \& Hernacki, 1992). Penulis berusaha meneliti bagaimana kondisi mereka setelah diterapkannya model pendidikan quantum learning di pondok pesantren AR. Fakhruddin Prambanan dalam setiap prosesnya dan mengoptimalisasikan potensi atau kemampuan dasar yang dimiliki oleh manusia.

Berdasarkan wawancara dengan Direktur MBS Yogyakarta Ust Fajar Sodiq, 20 November 2020 kita dapapat mengetahui bahwa pondok pesantren AR. Fakhruddin Prambanan merupakan sesuatu lembaga pembelajaran agama yang berkembang dengan sistem asrama. Walaupun berbasis sebagai sekolah agama, Pondok pesantren memiliki program unggulan keislaman yang merupakan pengembangan dari metode quantum learning yang meggabungkan aspek sugestology, teknik percepatan belajar dan neurolinguistik (NLP), para siswa diarahkan mengikuti kegiatan yang telah ditetapkan pondok pesantren, diantaranya yaitu Kegiatan Ikatan Pemuda Muhammadiyah (IPM), Tapak Suci (TS), Hizbul Wathan (HW), khitobah, membaca hadits, Bimbingan Baca Qur'an (BBQ) dan Jam'iyyah (sejenis kultum atau muhadhoroh) yang dilakukan secara kontinu.

Persiapan ini dapat dimulai dengan lingkungan fisik yang sebenarnya, yang diperindah dengan tanaman, seni dan musik. Lingkungan emosional pun mendapat perhatian yang tak kalah pentingnya. Pembimbing juga perlu memahami metode quantum learning sehingga 
mampu membentuk hubungan pengertian (De Porter \\& Mike Hernacki, n.d.). Adanya metode quantum learning merupakan strategi belajar yang memberikan gambaran yang menyenangkan dalam setiap prosesnya dan mengoptimalisasikan potensi atau kemampuan dasar yang dimiliki oleh manusia.

\section{Hasil dan Pembahasan}

Pendekatan pembelajaran dengan konsep quantum learning merupakan sebuah konsep yang memegang kuat falsafah bahwasanya belajar adalah kegiatan belajar seumur hidup, diterapkan dalam kelas dengan cara yang asik, juga disajikan dengan metodologi yang didasarkan pada kurikulum. Ini merupakan perpaduan antara keterampilan akademis, prestasi fisik dan keterampilan hidup. Sekilas pendekatan quantum ini sangat relvan dengan falsafah pendidikan sepanjang hayat yang menjadi pijakan dalam pendidikan Islam (Zayadi, 2017). Dalam Islam, tidak mengenal batasan usia dalam menuntut ilmu, oleh karena itu semua kalangan berhak untuk terus menuntut ilmu, dan hal ini tidak terlepas dari proses pendidikan.

Adapun metodologi pembelajaran yang diterapkan dalam quantum learning secara konseptual tidak berbeda dengan metodologi pendidikan Islam, keduanya melakukan pendekatan secara psikologis, menyentuh sisi emosional siswa dengan membangkitkan semangat (motivasi) mereka untuk belajar sepanjang hayat dan dengan suasana yang menyenangkan (Zayadi, 2017). Dapat dibayangkan begitu banyaknya potensi yang terkandung pada diri santri namun betapa tidak mudahnya untuk mengenalinya, apalagi menggunakannya untuk mengakses keberhasilan mereka di dalam kelas. Dalam upaya menggunakan semua potensi itu haruslah berpegang kepada prinsip sebagai berikut:

1. Setiap orang berkemampuan untuk belajar

2. Setiap orang belajar dengan cara yang berbeda

3. Keyakinan sangat penting bagi keberhasilan seseorang

4. Penghargaan dan perhatian bagi tiap individu adalah penting

5. Belajar akan lebih efektif bila disajikan dalam keceriaan dan lingkungan yang menantang

6. Rasa aman dan percaya antara ustadz dan santri merupakan bagian proses belajar yang penting

7. Guru harus menunjukan semangat dan antusiasme untuk belajar

Metodepembelajaran ini untuk mewujudkan suasana kelas yang menyenangkan. Suasana kelas adalah penentu psikologi utama yang mempengaruhi belajar. Adapun kunci untuk membangun suasana tersebut adalah:

1. Kekuatan Terpendam: Niat pendidik atau kekuatan akan kemampuan sangat berpengaruh pada kemampuan itu sendiri untuk dapat memotivasi siswa dan 
pandangan pendidik akan lebih cepat.

2. Jalinan Rasa Simpati dan Saling Pengertian: Dengan membangun jalinan rasa simpati dan saling pengertian dapat membangun jembatan menuju kehidupan dunia baru mereka, mengetahui minat kuat mereka dan berbicara dengan bahasa hati mereka.

3. Keriangan dan Ketakjuban: Keriangan dan ketakjuban dapat membawa siswa siap belajar dan lebih mudah dan bahkan mengubah sikap negatif. Bentuk keriangan atau kegembiraan yang biasa digunakan adalah: tepuk tangan, tiga kali hore, wuus, jentikan jari, poster umum, catatan pribadi, pengakuan kekuatan, kejutan, pujian pada teman sebangku, pernyataan afirmasi dan "wow".

4. Rasa Saling Memiliki: Rasa saling memiliki mempercepat proses pengajaran dan meningkatkan rasa tanggungjawab siswa misalnya: tepuk, wow, sebelum memulai belajar, menepuk segmen, mengakhiri segmen tertentu.

5. Keteladanan: Memberi teladan adalah salah satu cara ampuh untuk membangun hubungan dan memahami orang lain serta akan menambahkan kekuatan kedalam pembelajaran.

Pembelajaran quantum learning lebih mengutamakan keaktifan peran serta siswa dalam berinteraksi dengan situasi belajarnya melalui panca inderanya baik melalui penglihatan, pendengaran, perabaan, penciuman dan pengecapan (Hendriani, 2011). Quantum learning ialah kiat petunjuk, strategi dan seluruh proses yang dapat mempertajam pemahaman dan daya ingat, serta membuat belajar sebagai suatu proses yang menyenangkan dan bermanfaat. Oleh karena itu, untuk mengatasi kemandirian belajar rendah adapun treatmen yang digunakan adalah metode quantum learning. Kerangka pengajaran tersebut dalam pelaksanaannya dilakukan dengan enam langkah yang tercermin dalam istilah TANDUR, yaitu:

\section{Tumbuhkan}

Tumbuhan minat belajar siswa dengan motivasi rasa ingin tahu dalam bentuk: apakah Manfaatnya Bagiku, jika aku mengikuti topik pelajaran ini. Misalnya menanamkan "value/nilai (akhlak karimah/karakter islami). Setidaknya ada 13 karakter pendidikan agama (PAI) yang harus ditanamkan kepada siswa yaitu religius, jujur, disiplin, bertanggung jawab, cinta ilmu, ingin tahu, percaya diri, menghargai keberagaman, patuh pada aturan sosial, bergaya hidup sehat, sadar akan hak dan kewajiban, kerja keras, dan peduli. Keteladanan sangat penting bagi seorang pendidik untuk menumbuh kembangkan karakter atau prilaku terpuji kepada siswa, oleh sebab itu harus melakukan pilihan dalam berbagai hal. Dan ketika kita melakukan 
suatu pilihan konsekuensinya ada hikmah ada sangsi. menciptakan atau mendatangkan pengalaman umum yang dapat dimengerti semua siswa.

\section{Alami}

Cara apa yang terbaik agar siswa dapat berprilaku terpuji. Misalnya "tanamkan lima kata ajaib yang harus sering digunakan yaitu: salam, maaf, tolong, permisi, dan terima kasih. Pembiasaan siswa seperti ini dapat memberikan kontribusi yang besar dalam pola prilaku dalam kehidupan sehari-hari.

\section{Namai}

Setelah siswa melalui pengalaman belajar pada kompetensi dasar tertentu, kita ajak untuk menulis dikertas, menamai apa saja yang mereka peroleh, apakah informasi itu berupa gambar, tempat dan sebagainya kemudian mengajak mereka menempelkan hasilnya dipapan tulis. Hal ini bersenerji dalam jurnal yang di tulis oleh Rusniati yaitu, "Setelah siswa melalui pengalaman belajar pada topik tertentu, ajak mereka untuk membuat peta konsep dikertas, menamai apa saja yang telah mereka peroleh, apakah itu informasi, dalil naqli /aqli, pengalaman pribadi, dan sebagainya.

\section{Demonstrasikan}

Setelah siswa mengalami belajar akan sesuatu, beri kesempatan mereka untuk mendemonstrasikan kemampuaannya. Melalui pengalaman belajar siswa akan mengetahui dan mengerti bahwa dia memiliki pengetahuan dan informasi yang cukup memadai. Misalnya materi jual beli yang di istilahkan ijab qabul, materi dakwah, shalat, dan materi makanan da minuman sesuai dengan syariat. Melalui ini tentu siswa akan mudah mengingat materi yang di ajarkan. Mendemonstrasikan sebuah materi pun juga bisa dilaksanakan dikelas, masjid maupun di tempat terbuka.

\section{Ulangi}

Pengulangan akan memperkuat koneksi saraf. Ulangi pelajaran yang sudah berlalu melalui pancingan-pancingan pertanyaan kepada siswa dan hubungkan dengan pelajaran yang saat ini diajarkan. Dengan pengulangan demi pengulangan materi yang diajarkan akan setia pada memori otak siswa.

\section{Rayakan}

Pengakuan untuk penyelesaian, partisipasi, dan pemerolehan ketrampilan dan ilmu pengetahuan, bisa dilakukan dengan memberikan tepuk tangan maupun 
pemberian hadiah.

Quantum learning dimulai dari super camp, sebuah program akselerasi belajar yang memperkenalkan tiga keterampilan dasar, yakni keterampilan akademis, prestasi fisik, dan keterampilan hidup. Menurut penelitian, hasilnya demikian impresif. Setelah mengikuti kegiatan ini, motivasi belajar santri meningkat dan keterampilan belajar pun berkembang. Salah satu kunci keberhasilannya yaitu dengan mengetahui factor-faktor yang dapat mempengaruhi motivasi belajar siswa, berikut bagan yang dapat kita pahami untuk mengaplikasikan quantum learning dalam kelas kita.

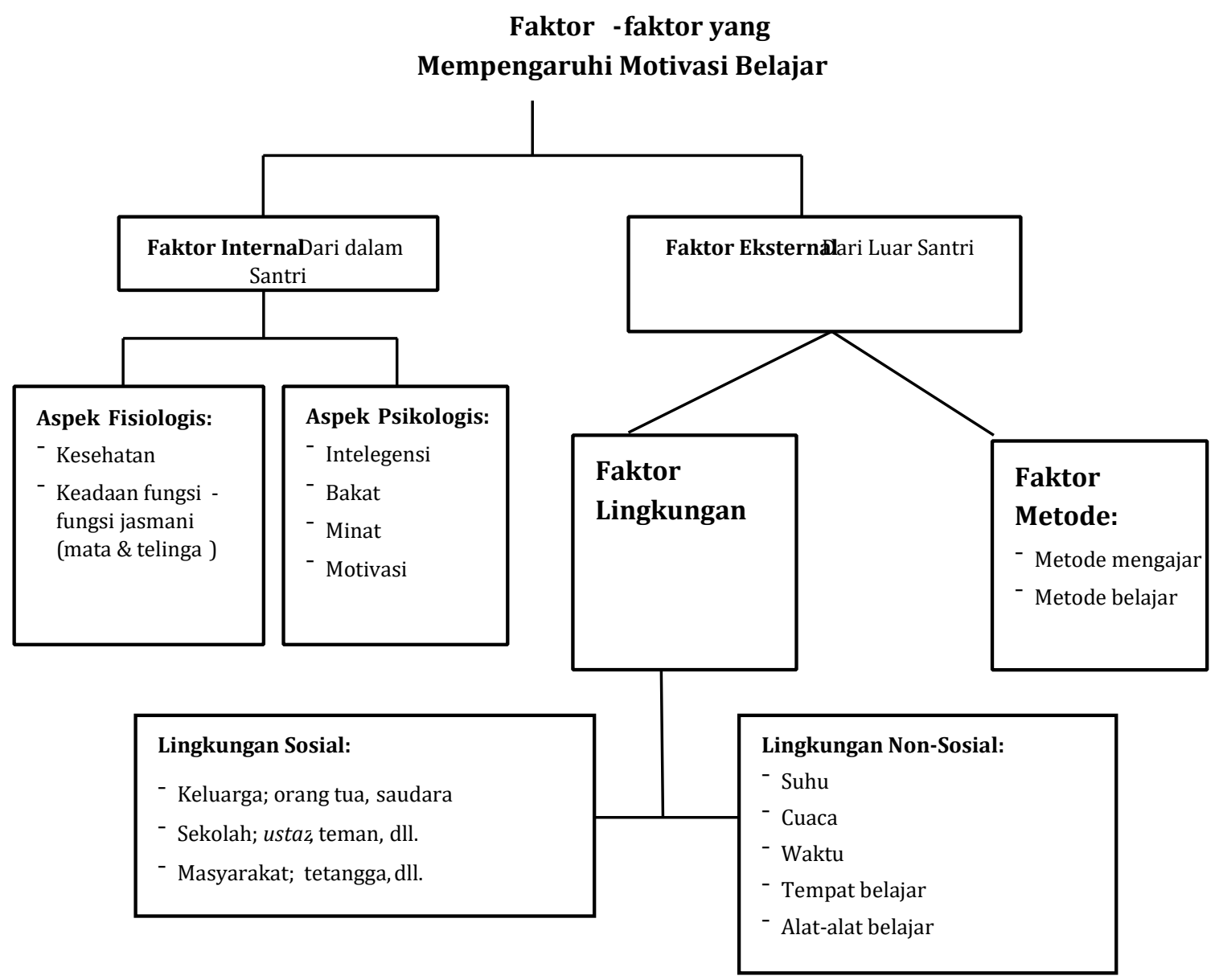

Gambar 1. Faktor-faktor yang mempengaruhi belajar siswa

Dalam peranannya pendidikan pesantren memiliki tiga prinsip utama, yaitu: Pertama, pesantren sebagai lembaga pengkaderan ulama, karena bagaimanapun pesantren adalah tempat belajar agama Islam jadi harus mencetak generasi ulama yang pandai tentang ilmu-ilmu Islam. Kedua, pesantren sebagai lembaga pengembangan ilmu-ilmu agama Islam. Ketiga, pesantren harus mampu menempatkan dirinya menjadi agen transformasi ilmu-ilmu keislaman seiring 
kemajuan zaman. Beberapa identitas khas yang ada di pesantren semisal:

1. Terdapatnya ikatan yang akrab antara murid serta guru.

2. Santri taat serta patuh.

3. Para santri hidup secara mandiri serta sederhana.

4. Semangat gotong royong dalam suasana penuh persaudaraan.

5. Para santri terbiasa terlatih hidup berdisiplin serta tirakat.

Ada tiga konsep kunci dari quantum learning yang hendak kita lihat dari sudut pandang pendidikan Islam. Pertama, pandangan tentang manusia; kedua tentang lingkungan yang mendukung proses pembelajaran dan yang ketiga metodologi pengajaran yang diterapkan. Lebih lanjutnya akan dipaparkan sebagai berikut:

\section{Pandangan Tentang Manusia}

Setiap manusia menurut quantum learning mempunyai potensi yang sama, perbedaan yang ada tidak lebih pada bagaimana manusia itu memanfaatkan otaknya. Pemikiran bahwa setiap orang mempunyai potensi yang sama, berdampak positif terhadap perkembangan anak didik. Setiap orang kemudian menyadari bahwa ia mempunyai peluang yang luar biasa besarnya. Pemahaman yang seperti ini, memungkinkan seseorang untuk meniru orang lain dan menggunakan orang itu sebagai model dengan mengatur pola berpikir dan tubuh yang seperti dia. Dalam quantum learning, seluruh pribadi adalah penting, baik akal, fisik maupun emosi/ pribadi.

Potensi ini dalam pendidikan pesantren lebih dikenal dengan fitrah (Chatib, 2012), yang mana bahwa fitrah manusia adalah kejadiannya sejak semula atau bawaan sejak lahir. Pondok pesantren AR. Fakhruddin berupaya untuk menampakkan secara maksimal potensi yang dimiliki oleh para santri yang notabene dari kalangan yatim dan dhuafa, tetapi memiliki kemampuan yang luar biasa. Dalam hal ini, pesantren berupaya untuk mengembangkan bakat dan kemampuan individual, sehingga potensi-potensi kejiwaan santri dapat diaktualisasikan secara sempurna. Potensi-potensi itu sesungguhnya merupakan kekayaan dalam diri manusia yang amat berharga.

Apabila dalam quantum learning semua kurikulum yang ada merupakan kombinasi dari tiga unsur; keterampilan akademis, prestasi fisik, dan keterampilan hidup, serta seluruh pribadi manusia dianggap penting, baik akal, fisik, maupun emosi/ pribadi. Maka dalam penerapannya para santri akan dibina dari unsur-unsur material (jasmani) dan immaterial (akal dan jasmani). Pembinaan akalnya 
menghasilkan ilmu, pembinaan jiwanya menghasilkan etika, sedangkan pembinaan jasmaninya menghasilkan keterampilan.

\section{Pandangan Tentang Lingkungan}

Dalam quantum learning, lingkungan bagi siswa sangat penting. Hal ini dimulai dengan lingkungan fisik yang diperindah dengan tanaman, seni dan musik. Ruangan juga dibentuk sedemikian rupa, agar terasa pas untuk kegiatan belajar seoptimal mungkin. Lingkungan emosional juga mendapat perhatian yang tak kurang seriusnya. Para pembimbing dalam quantum learning adalah para pakar yang membentuk jalinan pengertian, dan setelah mereka memantapkan daerah aman secara emosional, mereka menghadapkan para siswa pada tantangan-tantangan dimana mereka memperoleh kesuksesan waktu demi waktu.

Lingkungan pesantren sangatlah berpengaruh terhadap potensi santri. Untuk mengembangkan potensi/ kemampuan dasar santri, maka para santri membutuhkan adanya bimbingan dari para ustadz dan ustadzah, serta kiai, untuk membimbing, mendorong, mengarahkan agar berbagai potensi tersebut dapat tumbuh dan berkembang secara wajar dan optimal, sehingga kelak hidupnya dapat berdaya guna dan berhasil guna. Dalam arti yang luas lingkungan mencakup iklim dan geografis, tempat tinggal, adat istiadat, pengetahuan, pendidikan dan alam. Dengan kata lain, lingkungan ialah segala sesuatu yang tampak dan terdapat dalam alam kehidupan yang senantiasa berkembang. Ia adalah seluruh yang ada, baik manusia maupun benda buatan manusia.

Banyak orang yang mengira bahwa mengasuh anak yatim itu hanyalah memberikan nafkah kepadanya. Tidak diragukan bahwa ini adalah pemahaman yang sempit, meskipun memberikan nafkah itu juga memiliki pahala besar (K, n.d.). Akan tetapi pemahaman dari mengasuh anak yatim jauh lebih luas dari itu (Azizah, 2018).

Tidak jarang anak dari kalangan keluarga miskin tidak melanjutkan pendidikannya karena terhalang masalah ekonomi. Faktor biaya diperlukan karena belajar dan kelangsungannya sangat memerlukan biaya. Keluarga yang miskin akan merasa berat untuk mengeluarkan biaya. Pondok pesantren AR. Fakhruddin berupaya mengasuh anak yatim dan fakir miskin artinya memasukannya ke dalam tanggung jawab orang yang mengasuhnya. Artinya yakni menggabungkannya ke dalam keluarganya, lalu menafkahinya, mendidiknya dan mengajarinya adab dan akhlak yang baik sampai ia mencapai usia baligh (Husen, 2017). 


\section{Metodologi Pembelajaran}

Dalam penerapannya quantum learning di pesantren sangat memegang kuat falsafah bahwa belajar adalah kegiatan seumur hidup (Jannah, 2013) yang dapat dilakukan dengan menyenangkan dan berhasil dengan metodologi yang didasarkan pada kurikulum yang merupakan perpaduan antara keterampilan akademis, prestasi fisik, dan keterampilan dalam hidup, sangatlah relevan dengan falsafah pendidikan sepanjang hayat yang menjadi pijakan dalam pendidikan Islam.

Dalam pendidikan Islam metode pendidikan yang harus dipergunakan oleh para pendidik atau pengajar adalah yang berprinsip pada "child centered" yang lebih mementingkan anak didik dari pada pendidik sendiri. Menurut Ibn Khaldun metode pendekatan dalam pendidikan anak adalah yang bersifat psikologis (AL Manaf, 2020). Prinsip-prinsip yang disarankan adalah ; (1) Tidak memberi pelajaran yang sulit kepada para pemula, dan anak didik harus diberi persiapan secara bertahap yang menuju kesempurnaannya, (2) Memberi pelajaran yang sesuai dengan daya tangkap anak didik, (3) Jangan memberi ilmu yang melebihi kemampuan akal anak didik (Arifin, 1987).

Dalam hal metodologi pembelajaran, pendekatan psikologis dalam suasana yang hangat dan familiar dalam quantum learning secara esensial sangat relevan dengan suasana pesantren yang menginginkan kelembutan "soft approach" dalam proses pembelajaran. Metode-metode pembelajaran yang telah dirumuskan dalam al-Qur'an (Salamah \& Hidayatulloh, 2019) seperti: metode iswar, metode teladan, metode targhib dan tarhib, merupakan metode-metode yang memandang sudah lazim dipergunakan dalam hampir setiap interaksi pembelajaran di pesantren.

Proses pembelajaran tradisional menuju proses pembelajaran modern yang berbasis quantum learning telah dilakukan Pondok pesantren AR. Fakhruddin. Dengan melakukan perubahan ini suasana pembelajaran menjadi menyenangkan sehingga peserta didik yang belajar tidak merasakan sebuah beban tetapi menjadi suatu hal yang sangat mengasyikkan. Sehingga pondok pesantren AR Fakhruddin mempunyai quantum learning center yang berfungsi untuk terus menjaga mutu proses pembelajaran. Quantum Learning Center ini memiliki tugas untuk mengadakan pelatihan, membina, mengontrol proses pembelajaran dengan rutin, serta meingkatkan kompetensi pedagogik guru.

Walaupun berbasis sebagai pesantren yatim dan dhuafa, Pondok pesantren AR. Fakhruddin memiliki program unggulan keislaman yang tidak kalah hebat dengan pondok pesantren lain yang berbayar. Jadi, selain belajar pendidikan agama Islam, 
para santri pun mengikuti kegiatan yang telah ditetapkan pondok pesantren, diantaranya yaitu Kegiatan Ikatan Pemuda Muhammadiyah (IPM), Tapak Suci (TS), Hizbul Wathan (HW), khitobah, membaca hadits, dan Bimbingan Baca Qur'an (BBQ). Secara singkat kegiatan tersebut dapat dijelaskan sebagai berikut :

\section{Ikatan Pemuda Muhammadiyah (IPM)}

IPM adalah singkatan dari Ikatan Pelajar Muhammadiyah, yang merupakan organisasi otonom (ortom) dari Muhammadiyah. IPM bisa disebut juga organisasi Intra Sekolah atau biasa yang di sebut OSIS pada sekolah negeri, tetapi jika di sekolah Muhammadiyah IPM ini lah sebagai organisasi Siswa Intra Sekolah nya. IPM sebagai organisasi yang mewadahi kreativitas, pikiran, masukan, kritikan, dari siswa dan siswi.

\section{Tapak Suci (TS)}

Perguruan seni pencak silat ini didirikan pada tahun 1925 dan diberi nama Perguruan cik auman yang dipimpin langsung oleh Pendekar M.A Wahib dan Pendekar A. Dimyati, yaitu dua orang murid yang tangguh dari KH. Busyro Syuhada. Perguruan ini memiliki landasan agama dan kebangsaan yang kuat. Perguruan ini menegaskan seluruh pengikutnya untuk bebas dari syirik (menyekutukan Tuhan) dan mengabdikan perguruan untuk perjuangan agama dan bangsa.

Kegiatan ekstrakurikuler Tapak Suci di Pondok pesantren AR. Fakhruddin sendiri mempunyai tujuan untuk mengenalkan siswa pada budaya bela diri asli Indonesia agar kelak mereka dapat melestarikannya, kegiatan ekstrakurikuler ini juga bertujuan untuk mengembangkan minat dan bakat yang dimiliki oleh siswa serta bertujuan untuk menyiapkan siswa untuk mengikuti berbagai kompetisi di bidang bela diri Tapak Suci. Selain itu, Tapak Suci juga bertujuan untuk melatih siswa agar memiliki sifat disiplin, bertanggung jawab, dan percaya diri.

\section{Hizbul Wathan (HW)}

Gerakan Kepanduan Hizbul Wathan (disingkat HW) adalah salah satu organisasi otonom (ortom) di lingkungan Persyarikatan Muhammadiyah. HW didirikan pertama kali di Yogyakarta pada 1336 H (1918 M) atas prakarsa KH Ahmad Dahlan, yang merupakan pendiri Muhammadiyah. Prakarsa itu timbul saat dia selesai memberi pengajian di Solo, dan melihat latihan Pandu di alunalun Mangkunegaran. Gerakan ini kemudian meleburkan diri ke dalam Gerakan Pramuka pada 1961.

HW berasaskan Islam. HW didirikan untuk menyiapkan dan membina anak, remaja, dan pemuda yang memiliki aqidah, mental dan fisik, berilmu dan berteknologi 
serta berakhlak karimah dengan tujuan terwujudnya pribadi muslim yang sebenarbenarnya dan siap menjadi kader persyarikatan, umat, dan bangsa.

\section{Khitobah}

Khitobah adalah ceramah atau pidato yang mengandung penjelasan- penjelasan tentang sesuatu atau beberapa masalah yang disampaikan seseorang dihadapan sekelompok orang atau khalayak. Kegiatan ini bertujuan melatih mental dan keberanian santri berbicara di atas mimbar.

\section{Membaca hadits}

Pembacaan hadits dilakukan setiap hari setelah selesai shalat dhuhur, kegiatan ini juga melatih kemampuan santri dalam membaca dan menyampaikan materi di depan khalayak umum.

\section{Bimbingan Baca Qur'an (BBQ)}

Bimbingan Baca Qur'an merupakan kegiatan pembelajaran yang wajib diikuti seluruh santri (Budi Santoso, 2018). Diharapkan santri dapat membaca al-Qur'an dengan lancar serta memahami tajwidnya. Kegiatan ini kemudian dilanjutkan dengan menghafal al-Qur'an, jika sudah mendapatkan rekomendasi dari pembina untuk melanjutkan hafalan al-Qur'an.

\section{Daftar Pustaka}

AL Manaf. (2020). Pemikiran Ibnu Khaldun Tentang Pendidikan Dan Relevansinya Dengan Pendidikan Dunia. As-Salam: Jurnal Studi Hukum Islam \& Pendidikan, 9(1), 1-16. https://doi.org/10.51226/assalam.v9i1.116

Arifin, H. M. (1987). Filsafat Pendidikan Islam. Bina Aksara. https://books.google.co.id/books?id=qNhvAQAACAAJ

Azizah, N. (2018). PUTUSAN MK NO. 46/2010 TENTANG HUBUNGAN KEPERDATAAN ANTARA ANAK LUAR NIKAH DENGAN AYAH BIOLOGIS (ANALISIS DALAM PERSPEKTIF HUKUM ISLAM, HUKUM POSITIF, UIDHR, Dan UDHR). FITRAH:Jurnal Kajian Ilmu-IImu Keislaman, 4(2), 243. https://doi.org/10.24952/fitrah.v4i2.860

Budi Santoso, J. (2018). Pendampingan Bimbigan Membaca Al-Quran Dasar Metode Tsaqifa Santri Panti Asuhan Muhammadiyah Aimas. Abdimasa, 2(1), 37-42.

Chatib, M. (2012). Orangtuanya Manusia: Melejitkan Potensi dan Kecerdasan dengan Menghargai Fitrah Setiap Anak. Kaifa. https://books.google.co.id/books?id=QqeUAwAAQBAJ

De Porter $\backslash \&$ Mike Hernacki, B. (n.d.). Quantum Learning. PT Mizan Publika. https://books.google.co.id/books?id=6\%5C_Nx2\%5C_6T2cAC

DePorter, B., \& Hernacki, M. (1992). Quantum Learning: Unleashing the Genius in You. Dell Publishing. https://books.google.co.id/books?id=J\%5C_CunnywR-IC

Hendriani, A. (2011). Penerapan Metode Pembelajaran Quantum Learning Untuk Meningkatkan Hasil Belajar Siswa. Jurnal Administrasi Pendidikan, 13(1). https://doi.org/10.17509/jap.v13i1.6388

Husen, H. (2017). Metode Ta'dib dan Komunikasi Islami Menurut Perspektif Al-Qur'an dan Hadist dalam Pembangunan Karakter Anak Usia Dini. Golden Age: Jurnal Pendidikan Anak Usia Dini, 1(2), 43-50. https://doi.org/10.29313/ga.v1i2.3385

Islam, I. D. J. P. K. A. (1995). Filsafat pendidikan Islam. Bumi Aksara bekerjasama dengan Direktorat 
Jenderal Pembinaan Agama Islam,Departemen Agama. https://books.google.co.id/books?id=aS0OAQAACAAJ

Jannah, F. (2013). Pendidikan Seumur Hidup dan Implikasinya. Dinamika Ilmu, 13(1), 1-16. https://doi.org/10.21093/di.v13i1.19

K, M. M. (n.d.). Mari Mencintai Anak Yatim. Gema Insani. https://books.google.co.id/books?id=FAQJIn\%5C_hEuUC

Murcia, J. C., \& Sanchez, K. E. (2013). No 主観的健康感を中心とした在宅高齢者における 健康関連指標に関する共分散構造分析Title. Applied Microbiology and Biotechnology, 85(1), 2071-2079.

Pahnila, S., Siponen, M., Mahmood, A., Aalsalem, M. Y., Khan, W. Z., Gharibi, W., Khan, M. K., Arshad, Q., Al-Fadhli, M., Zaher, A., World Economic Forum, Khan, W. Z., Khan, K., Rashid, A., Danezis, G., Chivers, H., Lupu, E., Martin, A., Lewis, M., ... World Economic Forum. (2018). Bach. Yunof Candra Problematika Pendidikan Agama Islam PROBLEMATIKA. 2018 International Conference on Computing Sciences and Engineering, ICCSE 2018 - Proceedings, 16(3), 1-6. https://www.weforum.org/whitepapers/cyber-resilience-in-the-oil-and-gas-industry-playbookfor-boards-and-corporateofficers\%0Ahttps://doi.org/10.1016/j.jnca.2018.04.004\%0Ahttp://aisel.aisnet.org/pacis2007/7 3

Salamah, U., \& Hidayatulloh, A. (2019). POLA INTERAKSI USTADZ DAN SANTRI DALAM PEMBELAJARAN ( Studi Kasus di Pondok Pesantren Mambaul Hisan Blitar). J-PIPS (Jurnal Pendidikan Ilmu Pengetahuan Sosial), 6(1), 46. https://doi.org/10.18860/jpips.v6i1.7804

Tafsir, A. (1992). Ilmu pendidikan dalam perspektif Islam. Remaja Rosdakarya. https://books.google.co.id/books?id=12-dAAAAMAAJ

Zayadi, A. (2017). Quantum Learning dalam Perspektif Pendidikan Islam. Hikmah: Journal of Islamic Studies, 13(1), 115. https://doi.org/10.47466/hikmah.v13i1.84 